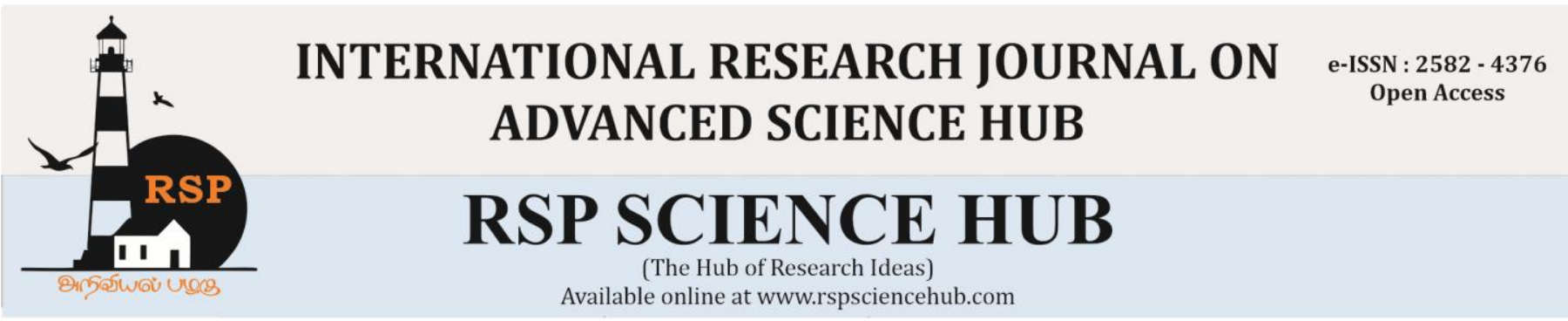

\title{
Review on Optimization of Metal Matrix Composite Connecting Rod
}

M.Haripriya ${ }^{1}$, G. Naga Malleswara Rao ${ }^{2}$, Dr.B.Durga Prasad ${ }^{3}$

${ }^{1}$ Phd Scholor, Mechanical Engineering Department, JNTUA, Anantapur, AP, India.

${ }^{2}$ Principal, Dept. of Mech Engg., Eswar College of Engg., Narasaraopet, AP, India.

${ }^{3}$ Professor \& Controller of Examinations, Dept. Of Mech. Engg., JNTUA, Anantapur, India. krishnapriya1418@gmail.com ${ }^{1}$

\begin{abstract}
Every vehicle runs on internal combustion engine and used at least one connecting rod in automobile field. More number of compressive and tensile forces is acting on the connecting rod due to fuel consumption so that failure can occur. To overcome this problem, carbon steel connecting rod is replaced by aluminium matrix composites due to good characteristics like better thermal conductivity, good heat transfer rate, lighter in weight, great strength, high stiffer and suitable for I.C. engine. In this investigation, a review has been attempted to find the better composite material and optimization of connecting rod in order to reduce the weight, displacement, strain, and stress by increasing the strength or by maintaining the strength. Also this review paper guides towards proper selection of reinforcement which has to be added to composite materials by considering economical and feasible manufacturing process in designing and production. Generally stir casting process is used for fabricating composites that are used in making connecting rods.
\end{abstract}

Keywords: Connecting rods, better composite material, mechanical properties, stir casting process.

\section{Introduction}

Practically connecting rods are used as intermediate link between piston and crankshaft in all varieties of automobile internal combustion engines to convert linear motion into rotational. Another function of connecting rod is transferring lubrication oil from crank pin to piston pin. It is subjected to cyclic tensile and compressive loads as highly stressed component. Generally the material used for connecting rod is ferrous material (example: carbon steel). Now in day the light weight materials (titanium and aluminium alloys or composites) are used due to desired mechanical properties.

Connecting rod should be lighter and consume less fuel and at the same time they should provide comfort and safety to passenger that unfortunately leads to increase the weight of the vehicle. This tendency in automobile field causes the optimization and implementation of new composite materials which are light in weight and meet desirable requirements.

Connecting rods are available in various sections like I-section, rectangular, circular, tubular or $\mathrm{H}$ section. Generally I-section is preferred for high speed engines which provide the maximum rigidity with minimum weight and circular section is used for low speed engines. Its strength and stiffness can be increased by changing its section or by changing some parameters of connecting rod. By changing the material of the connecting rod weight and cost can also be reduced. These are widely used in variety of engines such as, in-line engines, V-engine, opposed cylinder engines, radial engines and oppose-piston engines

It is subjected to various complex loads due to gas pressure \& the inertia forces of the reciprocating parts. The stresses induced into the connecting rod 
due to the thrust $\&$ the pull of the piston are bending stresses, tension \& compression in the axial direction. The connecting rod should be able to withstand these forces in unfavourable environmental conditions.

In general the titanium reinforced Aluminium metal matrix composites are used for connecting rod because of light weight, strength at low temperatures, good electrical and thermal conductivity, excellent corrosion resistant, low processing cost, having isotropic properties and chances of secondary processing. In aluminium metal matrix composites, aluminium is the base metal or matrix metal and titanium is chosen as reinforcement. By adding titanium to aluminium then the tensile strength and elongation of connecting rod may be increased to a greater extent. The application of aluminium metal matrix composites enables safety increase and leads to effective use of fuel and to evaluate high power of engine. Stir casting method is used to fabricate aluminium metal matrix composites due to the reason of easier, low production cost, and helps well in achieving uniform distribution of Particulates in the Matrix. Titanium is the best reinforcement for connecting rod.

\subsection{Materials Used}

Great attention should be paid on connecting rods, for the purpose of obtaining suitable cross section design, manufacturing process, material and its reinforcements. Material selection plays an important role in production of connecting rod. The material used for connecting rod should have fatigue strength \& resilience. Carbon steel connecting rods are replaced by new metal matrix composites (MMCs) which are an advanced materials resulting from a combination of two or more materials in which tailored properties are realized. Application of MMCs enables safety increase and advances that leads to effective use of fuel and to obtained high engine power

\subsection{Reinforcement Material}

The main duty of reinforcement in matrix metal is to carry and distribute the load. The reinforcement may be continuous and discontinuous fibers, whisker or particulates, in volume fractions ranging from $0 \%$ to $70 \%$ which depends on the wettability of matrix material. Then these are named as continuously reinforced composite and discontinuously reinforced composite. The addition of reinforcement to metal matrix increases the properties like stiffness, strength and temperature resistance capacity but lowers the density, ductility and fracture toughness of the composite. It is most important to select shape, size and type of reinforcement in order to obtain the best combination of properties at substantially low cost.

\subsection{Aluminium Matrix Composites (AMCS)}

In recent days there are few common materials like aluminium and Titanium are more preferable as composite materials of the connecting rod. Aluminium matrix composite (AMCs) connecting rod (in which aluminium is the base metal) having the properties like light weight, strength at low temperatures, relative stiffness, good electrical and thermal conductivity, excellent corrosion resistant, low processing cost and isotropic properties leads to more fuel savings, improved acceleration and good heat transfer rate so is suitable for I.C. engine. Titanium is also best material selected for I.C engine having good thermal conductivity and is easily available. In place of steel, if titanium alloy is used to manufacture connecting rod then tensile strength and elongation of connecting rod can be increased to a greater extend. The combination of materials like $\mathrm{Al}$ and Ti plays vital role in improvement of engine performance.

The properties of aluminium metal matrix composites can be tailored to the required demands of different industrial applications by selecting suitable combinations of matrix, reinforcement and methods. So that the aluminium matrix metal reinforced with titanium metal is the best composite material for connecting rod. Generally Aluminium matrix composites are fabricated using stir casting process.

\section{Literature Survey}

Prof. Rahul Bhandari, Dr. T. R. Vijayaram[1], In this research paper said that by adding small amount of reinforced metal in $\mathrm{Al}$, the hardness of $\mathrm{Al}$ increases drastically. If we add $2 \%$ of $\mathrm{TiO} 2$ to pure $\mathrm{Al}$ we can increase the hardness by almost $2 \mathrm{X}$, with increase of compaction pressure from 100 to $120 \mathrm{MPa}$ we get increase in Brinell value. Again if we want to increase hardness value just add $\mathrm{TiC}$ and $\mathrm{TiO} 2$ inclusion in Aluminium. By increasing compaction pressure by keeping sintering temperature same we can increase the hardness. Add the reinforcement in $2 \%$ or $4 \%$ or 
$6 \%$ or $8 \%$ each. Up to certain limit of addition of reinforcement in metal matrix the hardness increases. As Al is very light in weight and by adding very small amount of reinforcement into it the hardness increases which is very effective in applications where there is requirement of low weight high strength properties like in the field of aerospace and automobile.

\section{MarthanapalliHariPriya,}

K.Manohar

Reddy [2], in this paper explained, the weight of the connecting rod has little influence on the cost of the final component. Change in the material, resulting in a significant reduction in machining cost, was the key factor in cost reduction. This study has two aspects. The first aspect was to investigate and to compare fatigue strength of steel forged connecting rods with that of the powder forged connecting rods. The second aspect was to optimize the weight and manufacturing cost of the steel forged connecting rod. Constraints of fatigue strength, static strength, reducing inertia loads, reducing engine weight, improvised engine performance, fuel economy were also imposed. The fatigue strength was the most significant factor in the optimization of the connecting rod.

Mr. Rohit S. Phatale, Prof. B. S. Allurkar, Prof. S. M. Nagure[3], in this research paper concluded as In general, the use of composite materials helps in reducing the weight of the component without varying the boundary conditions, allowable stresses etc. Forging is the conventional method of manufacturing a connecting rod. Steel is heavier than aluminium and titanium. The combination of steel titanium or aluminium titanium has a better strength than any individual metal. $64.10 \%$ reduction in weight of connecting rod when forged steel and Al-Ti composite is compared. No much reduction in weight is observed for steel and composite of Steel-Ti but increased load carrying capacity.

\section{Rajeshkumar Gangaram Bhandare, Parshuram}

M. Sonawane[4], stated In case of MMC's, aluminum matrix composite due their high strength to weight ratio, low cost and high wear resistance are widely manufactured and used in structural applications along with aerospace and automobile industry also a simple and cost effective method for manufacturing of the composites is very essential for expanding their application. Reinforcements like particulate alumina, silicon carbide, graphite, fly ash etc can easily be incorporated in the melt using cheap and widely available stir casting method. The following variable parameters are to be considered, while preparing the MMC by stir casting, Speed of rotation, Stirring speed, Stirring temperature, Reinforcement preheat temperature, Stirring time, Pouring temperature, Mould temperature.

G.M Sayeed Ahmed et.al[5], Connecting rod made of forged steel is replaced with Aluminum alloys and Carbon Fiber. The materials are changed so that the weight of the connecting rod is less when aluminum alloys and carbon fiber are used by replacing Forged Steel. Analysis is done on the connecting rod using materials AA6061, AA7075, AA2014 and carbon fiber 280 GSM bidirectional. By observing the analysis results the stress obtained are very much less than their yield strength values.

M.Vamsi Krishna, Anthony.M.Xavior[6], in this research said that there are various reinforcements that have been tried out to develop AMCs are graphite, silicon carbide, titanium carbide, tungsten, boron, $\mathrm{Al}_{2} \mathrm{O}_{3}$, fly ash, $\mathrm{Zn}, \mathrm{TiB}_{2}$ or their combination to produce Hybrid composites. Addition of hard reinforcements such as silicon carbide, alumina, and titanium carbide improves hardness, strength and wear resistance of the composites. Aluminium alloys are still the subjects of intense studies, as their low density gives additional advantages in several applications. These aluminium alloys have started to replace bronze and cast iron, to manufacture wear resistant parts.

M K Surappa[7], In his research paper refer aluminium matrix composites (AMCs) as the class of light weight high performance aluminium centric material systems. Three decades of intensive research have provided a wealth of new scientific knowledge on the intrinsic and extrinsic effects of ceramic reinforcement vis-a-vis physical, mechanical, thermo-mechanical and tribological properties of AMCs. In the last few years, AMCs have been utilised in high-tech structural and functional applications including aerospace, defence, automotive, and thermal management areas, as well as in sports and recreation. It is interesting to note that research on particle-reinforced cast AMCs took root in India during the 70's, attained industrial maturity in the 
developed world and is currently in the process of joining the mainstream of materials.

C. Saravanan[8] et.al Stated the combined effect of reinforcements on Aluminum Metal Matrix composites with individual and multiple particulate reinforcements like Hybrid Metal matrix composites, which are finding increased applications in automobile, aerospace and transportation applications. This is mainly due to improved mechanical and tribological properties like strength, impact resistance, stiffness, abrasion and wear resistance.

M. Sonawane[9], studied that the past few years the global need for low cost, high performance and good quality materials has caused a shift in research from monolithic to composite materials. In case of MMC's, aluminum matrix composite due their high strength to weight ratio, low cost and high wear resistance are widely manufactured and used in structural applications along with aerospace and automobile industry. Also a simple and cost effective method for manufacturing of the composites is very essential for expanding their application. Reinforcements like particulate alumina, silicon carbide, graphite, fly ash etc can easily be incorporated in the melt using cheap and widely available stir casting method. The following variable parameters are to be considered, while preparing the MMC by stir casting, Speed of rotation, Stirring speed, Stirring temperature, Reinforcement preheat temperature, Stirring time, Pouring temperature, Mould temperature .

Qiu , J.W., Y. Liu ,Y.B. Liu ,B. Liu , B. Wang, E. Ryba , and H.P. Tang[10], in this research paper explained as new powder metallurgy $(\mathrm{P} / \mathrm{M})$ titanium alloy connecting rod with the composition of $\mathrm{Ti}-1.5 \mathrm{Fe}-2.25 \mathrm{Mo}$ (wt.\%), formed by a powder forging process, was successfully developed with the help of a pre-processing simulation using a commercial finite element software (DEFORM3D). The microstructures and the mechanical properties of the deformed material were evaluated. The results indicate that the microstructures of the crank pin end, fork part and piston pin end are lamellar $\alpha+\beta$ structures and the microstructure of shank is of through-transus bimodal phase. The tensile strength and elongation are much higher than those of the most widely used PF-11C50/60 steels, and can well meet the requirements of the connecting-rod industry. This process enhances the microstructure and the mechanical property of connecting rod. In place of steel, if titanium alloy is used to manufacture connecting rod by this method then tensile strength and elongation of connecting rod can be increased to a greater extend.

Kuldeep B, Arun L.R, Mohammed Faheem et.al[11], Comparative study was carried out on connecting rod by replacing the existing material with aluminum based composite material reinforced with fly ash and silicon carbide. Weight can be reduced and strength can be achieved by changing the material of the current connecting rod to hybrid composites. Finally obtaining the new optimized connecting rod which is comparatively much stiffer than the former.

\section{Frank linemmanuel.T, R.Natarajan[12],} concluded that now a day the Connecting rod are made up of aluminum silicon alloy, C-70 steel, Carbon epoxy Material which expands enormously due to generation of heat in the piston. This will affect clearance volume and insufficient clearance can cause the piston size in the cylinder. The ultimate aim is to reduce the expansion and increasing service factor by material and design modification and to analyze the various characteristics of Connecting rod like stress, deformation, density, Young's modules and poisons ratio in phase II .

Sahil Guleria[13], have discussed in his paper as the analysis performed in this project gave scope for optimization. Analysis of different parameters it has Suggested modification in existing connecting rod, from the analysis came to know that composite material can be a best alternate of conventional structural steel connecting rod due to light weight and high strength to weight ratio. The stress multiaxiality is high, therefore multiaxial fatigue analysis is needed to determine fatigue strength and the maximum stresses occurred in static structural analysis are less than the yield strength of material. Hence the design is safe.

Gubbala Eswara Kumar, G.S.V.Seshu Kumar[14], concluded that the aluminum metal matrix composites sought over the conventional materials in the field of aerospace, automotive and marine application owing to their excellent improved properties such as hardness and tensile strength at room and elevated temperatures and hence metal matrix composites are being 
extensively used. These materials are of much interested to researches from few decades.

\section{P. Gurusamy, S. Balasivanandha Prabu, and}

R. Paskaramoorthy[15], in this research paper deals with the influence of melt and die temperatures on the squeeze cast silicon carbide particulate reinforced aluminum alloy composites. The results reveal significant influence of both melt and die temperatures on the mechanical properties. The optimum melt and die temperatures for the preparation of the composite are $850^{\circ} \mathrm{C}$ and $350{ }^{\circ} \mathrm{C}$, respectively. Tensile and impact strengths, and hardness of composite samples prepared at this temperature combination are found to be better than those of samples prepared at other temperatures. Additionally, microstructures of samples prepared at this temperature combination display a relatively fine grain structure and the smallest degree of particle agglomeration which explain the dependence of mechanical properties on the melt and die temperatures.

\section{Conclusions}

The objective of current review is to optimize the better composite material of connecting rod with best combination of base metal and reinforcement. Connecting rods are subjected to mass and gas forces, results in axial stresses so that it must be capable of transmitting axial tension, compression, and bending stresses caused by the thrust and pull on the piston. The developed forces due to engine operation are greatly influenced by weight of the connecting rod; therefore it is important to reduce the weight of the connecting rod. It is possible to optimize the weight by using composite materials without varying the allowable stresses and boundary conditions.

Compare to standard materials the composite material offers great mechanical strength, high stiffness; light weight, lesser wear, fatigue life and resistance to corrosion are greatly improved. Aluminium composites are advanced materials due to their enhanced mechanical, electrical, thermal properties and cost effectiveness as compared to other engineering materials. The study through the several literature papers related to AMMCs, it has been reported as Aluminium is a feasible base metal to obtain desired properties by reinforcing with light weight materials like titanium. By adding titanium to aluminium matrix, the properties like hardness and tensile strength becomes increase. Stir casting technology is the least expensive process to fabricate AMCs.

From the current literature, it may be concluded that aluminium matrix composites (where aluminium is base metal and titanium is reinforcement metal) are better composite materials for connecting rods.

\section{References}

[1].Mr. Azeem Dafedar, Prof. Rahul Bhandari, Dr. T. R. Vijayaram, "Processing \& Characterization Of Titanium Carbide \& Titanium Oxide Particulate Reinforced Aluminium Metal Matrix Composite For Aerospace Applications", International Journal of Scientific \& Engineering Research, Volume 5, Issue 10, October2014, ISSN 2229-5518.

[2].M.HariPriya, K.Manohar Reddy, "Materialized Optimization of Connecting Rod for Four Stroke Single Cylinder Engine" International Journal of Computational Engineering Research $\|$ Vol, 03||Issue, 10.

[3].Mr. Rohit S. Phatale, Prof. B. S. Allurkar, Prof. S. M. Nagure, "Weight Optimization Of Connecting Rod Using Titanium Insert" ESHM-17,29 january 2017,ISBN:978-9386171-25-2.

[4]. Rajeshkumar

Gangaram Bhandare,Parshuram M. Sonawane, "Preparation of Aluminum Matrix Composite by Using Stir Casting Method", International Journal of Engineering and Advanced Technology, 2013, Volume-3, Issue-2, PP 2249 - 8958.

[5].G.M Sayeed Ahmed, Sirajuddin Elyas Khany, Syed Hamza Shareef," Design, Fabrication and Analysis of a Connecting Rod with Aluminum Alloys and Carbon Fiber", International Journal of Innovative Research in Science, 2014,Vol. 3, Issue 10, PP 16674-16687.

[6].M.Vamsi Krishna, Anthony.M.Xavior, "An Investigation on the Mechanical Properties of Hybrid Metal Matrix Composites", 12th Global Congress On Manufacturing And Management, 2014, PP 918 - 924.

[7].M K SURAPPA, "Aluminum matrix composites: Challenges and 
opportunities",2003, Vol. 28, PP 319-334.

[8].C. Saravanan, K. Subramanian, V. Ananda Krishnan, R. Sankara Narayanan, "Effect of Particulate Reinforced Aluminum Metal Matrix Composite" Mechanics and Mechanical Engineering , 2015,Vol. 19, No. 1,PP 23-30.

[9].Rajeshkumar Gangaram Bhandare, Parshuram M. Sonawane, "Preparation of Aluminum Matrix Composite by Using Stir Casting Method", International Journal of Engineering and Advanced Technology, 2013, Volume-3, Issue-2, PP 2249 - 8958.

[10].Qiu , J.W., Y. Liu ,Y.B. Liu ,B. Liu , B. Wang, E. Ryba , and H.P. Tang.2012. "Microstructures and mechanical properties of titanium alloy connecting rod made by powder forging process." Materials and Design 33: 213-219.

[11].Kuldeep B, Arun L.R, Mohammed Faheem, "Analysis And Optimization Of Connecting Rod Using Al, Fly ash, Sic Composites", International Journal of Innovative Research in Science, Engineering and Technology,2013,Vol. 2, Issue 6, PP 2480-2487.

[12].Frank linemmanuel.T, R.Natarajan “ Increasing The Service Factor Of Connecting Rod By Material And Design Modification Of 85bhp Tractor" iosr journal of mechanical and civil engineering (iosr-jmce) e-issn: 2278-1684, p-ISSN: 2320-334.

[13].Sahil Guleria "Optimization Of Steel Connecting Rod By Aluminum Connecting Rod Using Finite Element Analysis" International Journal of Advance research, Ideas and Innovations in Technology. Volume 1, Issue 1.

[14].Gubbala Eswara Kumar, G.S.V.Seshu Kumar, "Fabrication And Testing Of Aluminium Metal Matrix Composites Through Stir Casting Technique", IRJET, Volume: 05 Issue: 06 | June-2018, e-ISSN: 2395-0056.

[15].P. Gurusamy, S. Balasivanandha Prabu, and R. Paskaramoorthy, "Influence of Processing Temperatures on Mechanical Properties and Microstructure of Squeeze
Cast Aluminum Alloy Composites" Copyright \# Taylor \& Francis Group, LLC ISSN: 1042-6914 print=1532-2475 online. 